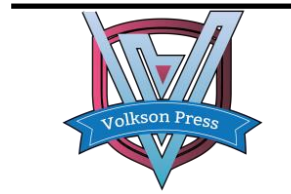

Contents List available at VOLKSON PRESS

Medical and Pharmaceutical Research (MPR)

DOI : http://doi.org/10.26480/wcmpr.01.2018.34.38

Journal Homepage: http://www.topicsonbiomed.com//

\title{
THE EFFECTS OF GERMINATION ON THE PHENOLIC ACIDS AND ANTIOXIDANT ACTIVITY OF PURPLE PERILLA (PERILLA FRUTESCENS VAR. ACUTA) SPROUTS
}

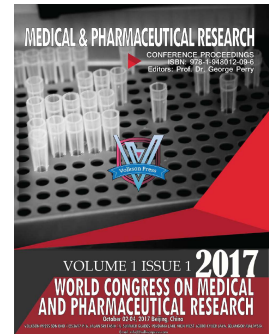

HongKai Liu1*, YuFan Kang2, JingRuo Tian3, YunPeng Liu4, XiaoWei Zhang1, ShuJie Zhang2, Han Sun1, XiaoYan Zhao1*

1 Culinary Institute, University of Jinan,Jinan 250002, China

2 College of Agronomy and Bitechnology, China Agricultural University,Beijing 100193, China

3 Department of Nutrition and Culinary, Shangdong College of Tourism and Hospitality, Jinan 250200,

China 4 School of Biological and Environmental Engineering, Binzhou University Binzhou 256600,

China

*Corresponding Author Email: sm_liuhk@ujn.edu.cn, st_zhaoxy@ujn.edu.cn

This is an open access article distributed under the Creative Commons Attribution License, which permits unrestricted use, distribution, and reproduction in any medium, provided the original work is properly cited

ARTICLE DETAILS

\section{ARTICLE HISTORY:}

Received 23rd January 2018

Accepted 23rd January 2018

Availableonline23rdJanuary 2018

\section{KEYWORDS:}

germination, phenolic compounds, antioxidant capacity, purple perilla sprouts
In this study, the influence of germination on the phenolic profile and antioxidant activities of purple perilla sprouts was investigated. The results demonstrated that the total phenolic content, total flavonoid content, and antioxidant activities of purple perilla sprouts significantly increased $(p<0.05)$ when compared to those of purple perilla seeds. The maximum amount of the total phenolic content was found to be $23.78 \mathrm{mg}$ GAE/g DW at the first stage (G1), which was an increase of $142.98 \%$ when compared with those of the seeds. The total flavonoid content reached the maximum value of $95.38 \mathrm{mg} \mathrm{RE} / \mathrm{g}$ DW, which was up $316.50 \%$ when compared with those of the seeds at the G2 stage. Among the six phenolic compounds which were identified and quantified, five significantly increased during germination. These findings suggested that germination can be used as a new approach for the further development of purple perilla sprouts as a potential food for human consumption.

\section{INTRODUCTION}

Purple perilla (Perilla frutescens var. acuta) is an annual eatable herbaceous plant native to Asia, which belongs to the Lamiaceae family $[1,2]$. It has been consumed as an edible vegetable, and can be used in food ingredients, oil crops, or medicinal materials [3,4]. Perilla seeds contain approximately $51 \%$ total lipids, and its essential oils are used in perfumes, soaps, detergents, and cosmetics $[5,6]$. Purple perilla leaves are used in salads, sushi, and soups, as well as pickles and garnishes [3]. Several studies have suggested that Perilla frutescens leaves and oils display a range of biological activities, including antiallergic, antiinflammatory, antitumour, antioxidant, and antiimmune characteristics, which have been attributed to phenolic compounds such as caffeic acid, rosmarinic acid , rosmarinic acid methyl ester, and triterpene acids [7-14]. Phenolic acids seem to have the greatest healthpromoting potential as a result of their scavenging free radicals, inhibition of lipid peroxidation, and thus their anticancer activity [15].

Germination is an inexpensive and effective method for increasing the nutritive and health qualities of plants [16]. Many studies have been conducted regarding the changes in phenolic compounds, as well as the antioxidant activities, of germinated seeds. There some researchers reported that the content of phenolic profiles and antioxidant activities increased significantly during the germination of buckwheat [17]. Other researchers reported that thirteen germinated edible seeds (mung bean, alfalfa, fava, fenugreek, mustard, wheat, broccoli, sunflower, soybean, radish, kale, lentil, and onion) were excellent sources of dietary phenolic antioxidants [18]. Some group researchers also have reported that germination increased the total phenolic and flavonoid levels, as well as the AA of the seeds, and also influenced the profile of the free and bound phenolic compounds during the germination of mung beans, radish, broccoli, and sunflowers [19]. However, almost no information exists to date concerning the effects of germination on the phenolic acids and antioxidant activities of purple perilla seeds.

Therefore, the objectives of the present study were to investigate the effects of germination on the phenolic phenolic acids, as well as the antioxidant activities in the seeds and sprouts of purple perilla. The expectation was to provide some scientific basis for the further development of purple perilla sprouts as a potential food for human consumption.

\section{MATERIALS AND METHODS}

\subsection{Materials}

In this study, the purple perilla seeds (Perilla frutescens var. acuta) were provided by the Beijing Lvshangu Sprouts Co., Ltd. (Beijing, China).

\subsection{Chemicals and reagents}

The standard phenolic compounds were procured from the SigmaAldrich Chemical Co. (St. Louis, MO, USA). The HPLC chromatograms of mix seven phenolic compounds standards as detected at $280 \mathrm{~nm}$ are presented in Figure 1. The HPLC-grade solvents were purchased from the Fisher Chemical Co. (Shanghai, China). All of the other chemicals and reagents used were of analytical grade.

\subsection{Germination of purple perilla}

In this study, the purple perilla seeds were washed with distilled water. Then, the seeds were soaked in water for 12 hours at room temperature. The imbibed seeds were distributed evenly in a germination tray containing many holes and were washed every 12 hours under dark conditions. The germination of the seeds was carried out at room temperature. The sprouts were harvested after $2,4,6$, and 8 days (G1, G2, G3, and G4) from the sprouts placed in the environment with a cycle of light and dark. Then, the sprouts were frozen in liquid nitrogen, freeze-dried, milled, and stored at $-40{ }^{\circ} \mathrm{C}$ awaiting further analysis.

\subsection{Determination of the total phenolic contents(TPC)}

The sample was extracted as described by other researchers, with some modifications $[20,21]$. The freeze-dried sprout powder $(0.1 \mathrm{~g})$ was 
extracted and sonicated with a $10 \mathrm{~mL}$ solution of acetone/water/acetic acid $(70: 29.5: 0.5, \mathrm{v} / \mathrm{v} / \mathrm{v})$ for 30 minutes, followed by centrifugation (10000 rpm, 10 minutes). The supernatant was then used for the estimation of TPC, TFC, ABTS, FRAP, and reducing power. Extractions were performed for three replicates.

The total phenolic content was analyzed using theFolin Ciocalteu (FC) colorimetric method described previously [22]. Briefly, in a 96well microplate, an aliquot of $50 \mathrm{uL}$ of the sample extracts was mixed with50uL of the Folin-Ciocalteu reagent, followed by the addition of 50 $\mathrm{uL}$ of a sodium carbonate solution $(7.5 \%, \mathrm{w} / \mathrm{v})$. The mixture was stirred and measured at $765 \mathrm{~nm}$, after remaining in the dark for 30 minutes. A blank sample consisting of water and reagents was used as a reference. A sample color blank was examined using the sample and water in order to exclude the color interference of the sample extract. The results were expressed as the $\mathrm{mg}$ of gallic acid equivalents per $\mathrm{g}$ of dry weight (mg GAE/g DW). Every sample was then analyzed in triplicate.

\subsection{Determination of flavonoids contents(TFC)}

An $\mathrm{AlCl}_{3}$ method was adopted for the determination of the total flavonoids, with minor modifications [23]. Briefly, in a 96-well microplate, $50 \mathrm{uL}$ of the extracts were added to $20 \mathrm{uL}$ of $\mathrm{NaNO}_{2}(5 \%)$. After 5 minutes at $25^{\circ} \mathrm{C}, 20 \mathrm{uL}$ of $\mathrm{AlCl}_{3}(10 \%)$ were added, and the solution was allowed to stand for 5 more minutes. Then, the reaction mixture was treated with $130 \mathrm{uL}$ of $\mathrm{NaOH}(1 \mathrm{mM})$. At this point, the absorbance of the mixture was determined at $510 \mathrm{~nm}$ against a water blank. The results were expressed as the $\mathrm{mg}$ of rutin equivalents per $\mathrm{g}$ of dry weight (mg RE/ g DW), and every sample was analyzed in triplicate.

\subsection{Determination of ABTS cation radical-scavenging activity}

The ABTS free radical (ABTS+) scavenging capacity was determined by the aforementioned method, with slight modifications [24]. The ABTS+ stock solution was prepared by reacting the ABTS solution $(7 \mathrm{mmol} / \mathrm{L})$ with a potassium persulfate $(2.45 \mathrm{mmol} / \mathrm{L})$ solution, under dark conditions at room temperature for 12 to 16 hours before use. The ABTS+ working solution was prepared by diluting the stock solution with a phosphate buffer $(\mathrm{pH}$ 7.4) to an absorbance level of 0.75 to 0.80 at $734 \mathrm{~nm}$. Briefly, in a 96-well microplate, $10 \mathrm{uL}$ of the extracts were added to $190 \mathrm{uL}$ of the ABTS+ working solution. The absorbance of the mixed solution at $734 \mathrm{~nm}$ was recorded after 10 minutes in the dark conditions. The inhibition percentage of ABTS+ was calculated as follows:

Inhibition $_{\text {sample }}(\%)=\left(\mathrm{Abs}_{\text {control }}-\mathrm{Abs}_{\text {sample }}\right) / \mathrm{Abs}_{\text {control }} \times 100$

Where $\mathrm{Abs}_{\text {control }}$ is the absorbance of the control sample, and $\mathrm{Abs}_{\text {sample }}$ is the absorbance of the sample.

Then, the results for the ABTS+ scavenging capacity of the samples were expressed as a trolox equivalent antioxidant capacity. Atrolox standard curve was built by plotting the inhibition percentage versus the trolox concentration at $734 \mathrm{~nm}$ for the ABTS assays. As before, every sample was analyzed in triplicate.

\subsection{Determination of Ferric reducing antioxidant power (FRAP)}

FRAP assay was conducted according to the method described by a group researcher, with some modifications [25]. The working FRAP solution was freshly prepared by mixing anacetate buffer $(300 \mathrm{mM}$, pH3.6), $10 \mathrm{mM}$ TPTZ (2,4,6-Tris(2-pyridyl)-s-triazine) solution in 40 $\mathrm{mM} \mathrm{HCl}$, and a $20 \mathrm{mM}$ ferric chloride solution at a ratio of 10:1:1. The working solution was warmed at $37^{\circ} \mathrm{C}$ before usage. Briefly, in a 96well microplate, $10 \mathrm{uL}$ of the extracts were mixed with a $290 \mathrm{uL}$ FRAP solution at one-minute intervals. After four minutes of incubation at $37^{\circ} \mathrm{C}$, the absorbance was read at $593 \mathrm{~nm}$. A calibration curve was made using ferrous sulphate. This was expressed as $\mathrm{mM} \mathrm{Fe}^{2+}$ per $\mathrm{g}$ dried weight $\left(\mathrm{mM} \mathrm{Fe}^{2+} / \mathrm{g} \mathrm{DW}\right)$, and every sample was analyzed in triplicate.

\subsection{Determination of Reducing power}

The reducing power of the extracts was determined using the process described by others group researchers, with some modifications [26]. Briefly, an aliquot of $100 \mathrm{uL}$ extracts was mixed with $100 \mathrm{uL}$ potassium ferricyanide $(1 \%, \mathrm{w} / \mathrm{v})$ in a phosphate buffer $(0.2 \mathrm{M}, \mathrm{pH}$ 6.6). The mixture was incubated at $50^{\circ} \mathrm{C}$ for 20 minutes, and then added to $50 \mathrm{uL}$ of trichloroacetic acid $(10 \%, \mathrm{w} / \mathrm{v})$, followed by centrifugation at $3000 \mathrm{~g}$ for 10 minutes. The upper layer of the solution $(90 \mathrm{uL})$ was mixed with distilled water $(50 \mathrm{uL})$ and ferric chloride $(10 \mathrm{uL}, 0.1 \%$, w/v). Then, the absorbance was measured at $700 \mathrm{~nm}$ after 30 minutes. The blank contained all of the reagents with the exception of the sample extract. At this point, the results for the reducing power were expressed as a trolox equivalent antioxidant capacity. A trolox standard curve was built by plotting the inhibition percentage versus the trolox concentration at $700 \mathrm{~nm}$ for the reducing power assays, and every sample was analyzed in triplicate.

\subsection{HPLC analysis of the phenolic acids}

Freeze-dried samples $(2.0 \mathrm{~g})$ were extracted with $20 \mathrm{~mL}$ of methanol/water/methanoic acid $(80: 19: 1, \mathrm{v} / \mathrm{v} / \mathrm{v})$ for 20 minutes in a sonicator bath, which was shaken every 10 minutes using a vortex stirrer, and then centrifuged ( $3800 \mathrm{~g}, 10$ minutes). The extraction was repeated twice more, the supernates combined, and then concentrated at $40^{\circ} \mathrm{C}$ under vacuum conditions for methanol evaporation using a rotary evaporator. The extracts were dissolved in $1 \mathrm{~mL}$ of methanol: water solution $(1: 1, \mathrm{v} / \mathrm{v})$, and filtered through $0.22 \mathrm{um}$ micro-filter paper prior to the HPLC analysis.

The chromatographic separation was carried out using an HPLC (Thermo-ultimate 3000) equipped with a diode array detector (DAD). The analytical column was $250 \mathrm{~mm} \times 4.6 \mathrm{~mm}$ Innoval Neo XD C18 column. The mobile phase consisted of A ( $0.1 \%$ acetic acid in water), and B (acetonitrile). The conditions were set as follows: acolumn temperature of $35 \mathrm{C}$; flow rate of $1.0 \mathrm{~mL} / \mathrm{min}$; and injection volume of $20 \mathrm{uL}$. A 47-minute gradient was programmed as follows: 0 to 5 minutes, $15 \% \mathrm{~B} ; 5$ to 15 minutes, $25 \% \mathrm{~B} ; 15$ to 25 minutes, $35 \% \mathrm{~B} ; 25$ to 28 minutes, $35 \%$ B; 28 to 32 minutes, $40 \%$ B; 32 to 40 minutes, $95 \%$ $\mathrm{B}$; and 40 to 47 minutes, $15 \% \mathrm{~B}$. The phenolic acids were detected at a wavelength of $280 \mathrm{~nm}$. The phenolic compounds were identified by comparing the retention times with those of their respective standards. The contents of phenolic compounds were quantified using external calibration curves. The HPLC chromatogram of the six standards of phenolic acids is presented in Figure 1.

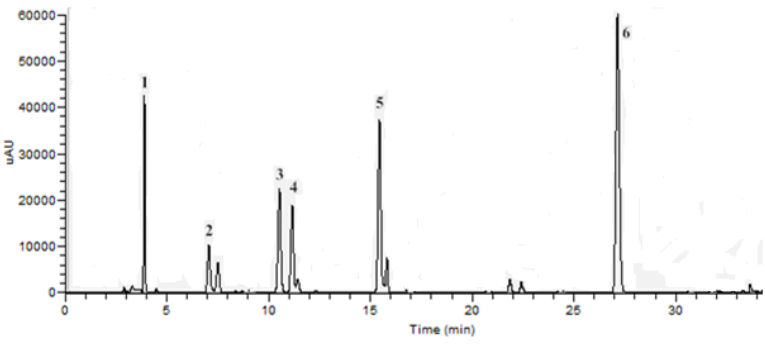

Figure 1: Representative UPLC-DAD chromatogram of mix seven standards as detected at $280 \mathrm{~nm}$. Peak numbers refer to the phenolic metabolites listed in Table 2. Peak no. 1, gallic acid; 2, chlorogenic acid; 3, caffeic acid; 4, syringic acid; 5, p-coumaric acid; 6, transCinnamic acid.

\subsection{Statistical Analysis}

The data were expressed as mean \pm standard deviation (SD). The data were analyzed by a one-way analysis of variance (ANOVA) and a posthoc Duncan test. A Pearson correlation test was used to evaluate the correlation among the variables. The differences of $\mathrm{p}<0.05$ were considered significant.

\section{RESULTS AND DISCUSSION}

\subsection{Total phenolic content (TPC)}

Germination can increase the content of intrinsic phenolic compounds and antioxidant activities due to the action of enzyme synthesis and kernel modification [27]. In this study, the TPC ranged from 12.74 to $23.78 \mathrm{mg}$ GAE/ g DW during the germination processes (G1-G4), which had increased by 29.61 to $142.98 \%$ when compared with those of the seeds (Figure 2A). The perilla seeds, leaves, and stems have been utilized as a folk medicine for treating intestinal disorders due to their several phenolic compounds [14]. Some researcher also reported the highest yield of the total phenolic of purple perilla leaves was found to be $12.15 \mathrm{mg} \mathrm{GAE} / \mathrm{g} \mathrm{DW}$, which was much less than that of the purple perilla sprouts at the G1 stage in this study [28]. Therefore, purple perilla sprouts have been confirmed to be a good source of phenolic content. 


\subsection{Total flavonoid content (TFC)}

The changes of the TFC at the different germination stages is presented in Figure 2B. The total flavonoid content was found to range from 35.49 to $78.97 \mathrm{mg} \mathrm{RE} / \mathrm{g}$ DW during the germination process (G1 to G4). Germination significantly increased the TFC, and its value reached a maximum of $95.38 \mathrm{mg} \mathrm{RE} / \mathrm{g} \mathrm{DW}$, which was an increase of $316.50 \%$, at the G2 stage. In fact, an increase of the TFC with the action of germination had already been described in previous studies [19, 23]. The activities of PAL, which is an important and rate-limiting enzyme for the biosynthesis of flavonoids and phenolic acids, were found to also be enhanced during germination. Therefore, the TFC increased during the germination process. The TFC of purple perilla sprouts was much higher than that of the leaves. The leaves' highest yield of total phenolic was $7.23 \mathrm{mg} \mathrm{RE} / \mathrm{g}$ DW [28]. The same phenomenon of the TFC has also been documented in broccoli sprouts, where it was found to be higher than that of the mature plants (Aires et al., 2011) [29]. These results further confirmed the higher TFC in purple perilla sprouts.
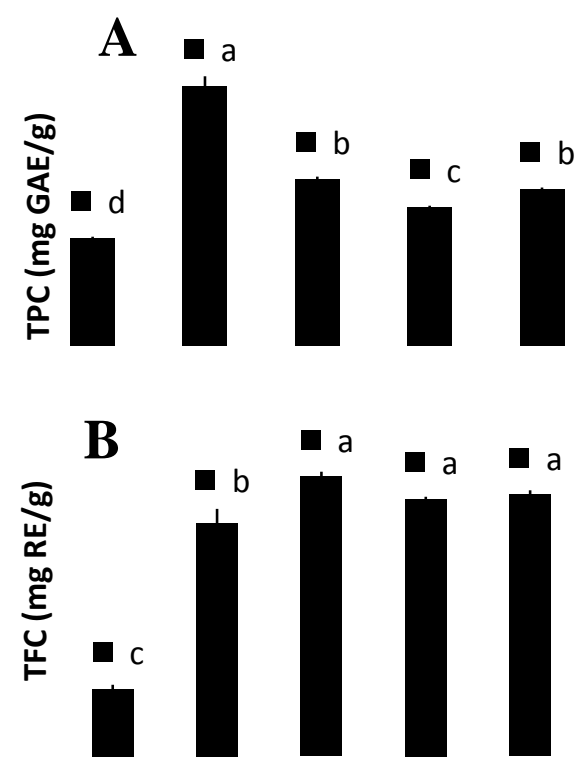

Figure 2: Influence of germination on the total phenolic content (TPC) (A) and total flavonoids content (TFC) (B) of purple perilla sprouts. Different small letters respectively indicate the significant differences at $p \leq 0.05$ level.

\subsection{Antioxidant capacity}

An increase in the content of phenolic compounds is linked to a subsequent elevation of antioxidant capacity. In this study, the antioxidant activities of purple perilla sprouts during germination were evaluated using the ABTS, FRAP, and reducing power assay methods. These assays have already been widely used to evaluate the antioxidant activity in lentil, mung beans, radish, broccoli, and sunflowers [19,30]. The antioxidant capacity of the purple perilla sprouts, which was determined by the ABTS, FRAP, and reducing power assay methods, are presented in Figure 3.

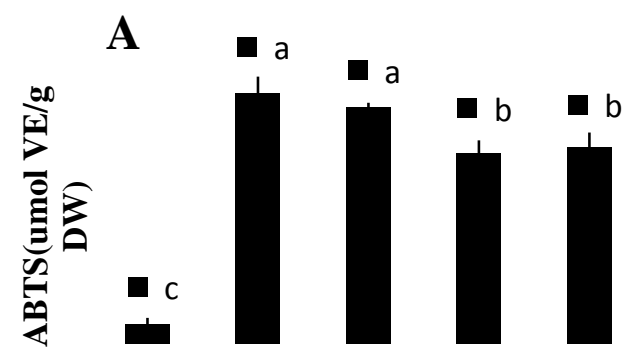

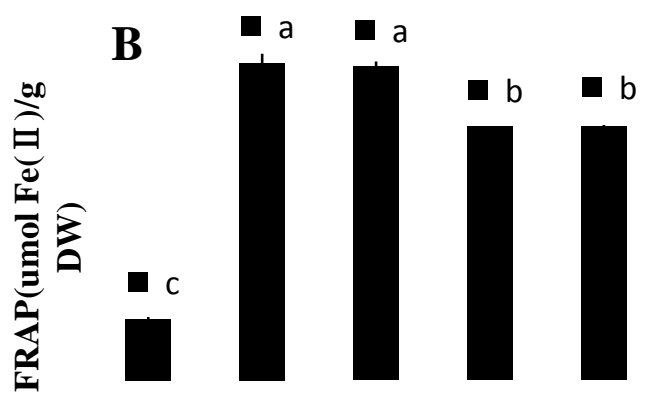



Figure 3: Influence of germination on the FRAP (A), ABTS(B) and reducing power(C) of purple perilla sprouts. Different small letters respectively indicate the significant differences at $p \leq 0.05$ level.

The ABTS radical cation can become reduced when exposed to antioxidants. In this study, the ABTS value ranged from 138.30 to 181.58 umol VE/g DW during the germination processes (G1 to G4), which had increased by 857.11 to $1156.64 \%$ compared with those of the seeds (Figure 3A). The ABTS value had increased significantly $(1156.64 \%)$ at the first stage (G1). Then, a gradual decrease in the ABTS value from stages G1 to G4 was observed. The ABTS value was determined to be the highest at the G1 stage. These results confirmed that the methanol extracts of purple perilla sprouts had a stronger antioxidant capacity to reduce the ABTS radical cation.

Ferric reducing activity is mainly influenced by the size of the conjugated double bond (CDB) system [25]. In the present study, the FRAP value ranged from 343.86 to $430.45 \mathrm{umol} \mathrm{Fe}$ (II)/g DW during germination processes (G1 to G4), which had increased by 313.69 to $417.86 \%$ when compared with those of the seeds (Figure 3B). The FRAP value had increased significantly $(417.86 \%)$ at the first stage (G1). Then, a gradual decrease in the FRAP value from stages G1 to G4 was observed. The FRAP value was determined to be the highest at the G1 stage. These results indicated that the antioxidants of purple perilla sprouts showed significant activity in the reduction of the $\mathrm{Fe}^{3+}$-TPTZ complex due to the high number of CDB.

The total reduction capability serves as a significant indicator of the potential antioxidant activity [22]. In this study, the reducing power value ranged from 112.28 to 118.15 umol $\mathrm{VE} / \mathrm{g}$ DWduring the germination process stages (G1 to G4) (Figure 3C). The reducing power value was found to gradually increase from 274.76 to $294.38 \%$ when compared with that of the seeds (29.54 umol VE/g DW). The highest level (118.15 umol VE/g DW) was reached in the G1 stage. An insignificant decrease in the FRAP value from stages G1 to G4 was observed.

It was determined that germination significantly increases the antioxidant capacity (ABTS, FRAP, and reducing power methods) of purple perilla sprouts [31]. Regarding lentils and kidney beans, and that which reported by some researchers regarding broccoli sprouts [32]. The increment of antioxidant capacity during germination seemed to be related to the rise in the content of antioxidants, such as vitamins and phenolic compounds. In the present study, the total flavonoid content, as well as the ABTS, FRAP, and reducing power methods, showed the significant correlation $\left(r^{2}=0.929,0.930,0.978\right.$, respectively) (Table 1). The total phenolic content and antioxidant activities shared a positive correlation. However, it did not reach the significant statistical level. There was a decrease in antioxidant capacity observed as the germination proceeded [33]. This may have been due to a high demand for oxygen during the early germination stage, and a lower demand for 
oxygen during the late germination stages. The increased phenolics may

\begin{tabular}{|c|c|c|c|c|c|c|}
\hline $\begin{array}{l}\text { Ger } \\
\text { min } \\
\text { atio } \\
\mathrm{n} \\
\text { time }\end{array}$ & $\begin{array}{l}\text { Gal } \\
\text { lic } \\
\text { aci } \\
\text { d }\end{array}$ & $\begin{array}{l}\text { Chlo } \\
\text { roge } \\
\text { nic } \\
\text { acid }\end{array}$ & $\begin{array}{l}\text { Caf } \\
\text { feic } \\
\text { aci } \\
\text { d }\end{array}$ & $\begin{array}{l}\text { Syri } \\
\text { ngic } \\
\text { acid }\end{array}$ & $\begin{array}{l}\text { p- } \\
\text { cou } \\
\text { mar } \\
\text { ic } \\
\text { aci }\end{array}$ & $\begin{array}{l}\text { Trans } \\
- \\
\text { Cinna } \\
\text { mic } \\
\text { acid }\end{array}$ \\
\hline Seed & $\begin{array}{l}3.2 \\
6 \pm 0 \\
.12\end{array}$ & $\begin{array}{l}\text { ND } \\
\mathrm{a}\end{array}$ & $\begin{array}{l}3.5 \\
8 \pm 0 \\
.23\end{array}$ & $\begin{array}{l}3.65 \\
\pm 0.2 \\
2 \mathrm{a}\end{array}$ & $\begin{array}{l}3.0 \\
2 \pm 0 \\
.12\end{array}$ & $\mathrm{ND}$ a \\
\hline G1 & $\begin{array}{l}5.0 \\
2 \pm 0 \\
.29\end{array}$ & $\begin{array}{l}81.4 \\
1 \pm 5 \\
75 \mathrm{~b}\end{array}$ & $\begin{array}{l}52 . \\
53 \pm \\
1.0\end{array}$ & $\begin{array}{l}33.4 \\
7 \pm 3 . \\
31 \mathrm{~d}\end{array}$ & $\begin{array}{l}1.7 \\
9 \pm 0 \\
.23\end{array}$ & $\begin{array}{l}9.13 \pm \\
0.52 \mathrm{~d}\end{array}$ \\
\hline G2 & $\begin{array}{l}4.9 \\
6 \pm 0 \\
.13 \\
\end{array}$ & $\begin{array}{l}105 . \\
31 \pm 5 \\
.48 \mathrm{c}\end{array}$ & $\begin{array}{l}76 . \\
35 \pm \\
3.9 \\
\end{array}$ & $\begin{array}{l}35.2 \\
6 \pm 2 . \\
70 \mathrm{~d}\end{array}$ & $\begin{array}{l}2.5 \\
3 \pm 0 \\
.18 \\
\end{array}$ & $\begin{array}{l}6.24 \pm \\
0.46 \mathrm{c}\end{array}$ \\
\hline G3 & $\begin{array}{l}5.0 \\
0 \pm 0 \\
.09\end{array}$ & $\begin{array}{l}203 . \\
40 \pm 6 \\
.84 \mathrm{~d}\end{array}$ & $\begin{array}{l}69 . \\
82 \pm \\
2.3\end{array}$ & $\begin{array}{l}28.5 \\
4 \pm 2 . \\
32 \mathrm{c}\end{array}$ & $\begin{array}{l}1.3 \\
2 \pm 0 \\
.11\end{array}$ & $\begin{array}{l}5.46 \pm \\
0.36 b\end{array}$ \\
\hline G4 & $\begin{array}{l}5.8 \\
4 \pm 0 \\
.28\end{array}$ & $\begin{array}{l}299 . \\
71 \pm 8 \\
.95 \mathrm{e}\end{array}$ & $\begin{array}{l}63 . \\
22 \pm \\
2.6\end{array}$ & $\begin{array}{l}17.9 \\
6 \pm 1 \\
76 \text { b }\end{array}$ & $\begin{array}{l}2.2 \\
2 \pm 0 \\
.09\end{array}$ & $\begin{array}{l}4.93 \pm \\
0.46 b\end{array}$ \\
\hline
\end{tabular}

have been protecting the cells from potential oxidation-induced deterioration during early germination, and increased the antioxidant capacity [16]

Table 1: The correlations between TPC, TFC and antioxidant activities.

\begin{tabular}{|c|l|l|l|l|l|}
\hline & $\begin{array}{l}\text { TP } \\
\mathrm{C}\end{array}$ & TFC & $\begin{array}{l}\text { ABT } \\
\mathrm{S}\end{array}$ & $\begin{array}{l}\text { FRA } \\
\mathrm{P}\end{array}$ & $\begin{array}{l}\text { Reduci } \\
\text { ng } \\
\text { power }\end{array}$ \\
\hline TPC & 1 & & & & \\
\hline TFC & $\begin{array}{l}0.44 \\
6\end{array}$ & 1 & & & \\
\hline ABTS & $\begin{array}{l}0.73 \\
9\end{array}$ & $\begin{array}{l}0.92 \\
9^{\mathrm{a}}\end{array}$ & 1 & & \\
\hline FRAP & $\begin{array}{l}0.72 \\
5\end{array}$ & $\begin{array}{l}0.93 \\
0^{\mathrm{a}}\end{array}$ & $\begin{array}{l}0.99 \\
9^{\mathrm{b}}\end{array}$ & 1 & \\
\hline $\begin{array}{l}\text { Reduci } \\
\text { ng } \\
\text { power }\end{array}$ & $\begin{array}{l}0.61 \\
2\end{array}$ & $\begin{array}{l}0.97 \\
8^{\mathrm{b}}\end{array}$ & $\begin{array}{l}0.97 \\
6^{\mathrm{b}}\end{array}$ & $\begin{array}{l}0.97 \\
1^{\mathrm{b}}\end{array}$ & 1 \\
\hline
\end{tabular}

Notes: ${ }^{\mathrm{a}}$ Significant correlation for $p<0.05 .{ }^{\mathrm{b}}$ Significant correlation for $p<0.01$.

\subsection{Phenolic acids}

In the present study, six phenolic acids, namely gallic chlorogenic, caffeic, syringic, p-coumaric, trans-cinnamic, were identified and quantified. The changes of the phenolic compounds are presented in Table 2.

It was determined that germination significantly increased the gallic, chlorogenic, caffeic, syringic, and trans-cinnamic acid contentsof purple perilla sprouts (Table 2). Gallic acid is widely recognized as having antioxidant and anti-tumor activities [34]. In this study, the gallic acid content gradually increased from a range of 5.02 to $5.84 \mathrm{ug} / \mathrm{g}$ DW during the germination process. Chlorogenic acid is widely recognized to have antioxidant activities, as well as a broad range of biological properties [35]. Trans-cinnamic acid has great potential for therapeutic use, and has shown antimicrobial, antifungal, and antitumour activities [36]. In this study, chlorogenic acid and trans-cinnamic acid were only detected in the seeds. The chlorogenic acid gradually increased from a range of 81.41 to $299.71 \mathrm{ug} / \mathrm{g}$ DW during the germination process, while the trans-cinnamic acid gradually decreased from $9.13 \mathrm{ug} / \mathrm{g}$ DW to $4.93 \mathrm{ug} / \mathrm{g}$ DW. Therefore, germination may increase the biological properties of purple perilla sprouts. The biological properties of caffeic and syringic acid, in particular their antioxidant activities, are well recognized [37]. In this study, their contents in purple perilla sprouts gradually increased from the G1 stage to the G2 stage, and then a decreased following the second stage (G2). In short, the germination may increase the biological properties of purple perilla sprouts via increasing the contents of phenolic compounds.

Table 2: Phenolic acids content of seed and sprouts extracts (ug/g DW) determined by HPLC

Data represent mean \pm SD of triplicate determinations. ND, not detected. Values with different letters within a column are significantly different $(P<0.05)$

Some group scientists detected three phenolic acids (coumaroyl tartaric, caffeic, and rosmarinic) in purple perilla leaves [9]. Other researchers detected nine phenolic acids (gallic, protocatechuic, pHydroxybenzoic, isovanillic, chlorogenic, caffeic, ferulic, sinapic, and rosmarinic) in purple perilla leaves [3]. In this study, six phenolic acids were identified and quantified. However, some of the phenolic acids were not detected in the reports by other researchers [3,9]. The differences in the detected phenolic acids may have been due to the different extraction conditions, chromatography systems employed and plant tissues [38].

\section{CONCLUSIONS}

The total phenolic content, total flavonoid content, and antioxidant activities in purple perilla seeds were determined to increase greatly after germination. six phenolic acids were identified and quantified, and five of these were observed to significantly increase during germination. The results of this study suggested that purple perilla sprouts are excellent nutritional sources of flavonoids and phenolic compounds. Also, it was determined that germination can be used as a new approach to the further development of purple perilla sprouts as a potential food for human consumption.

\section{ACKNOWLEDGEMENTS}

This work was supported by University of Jinan Science and Technology Planning Project (140200219), University of Jinan Doctoral Scientific Fund Project (160100231), Science and Technology Development Plan of Weifang City(2017ZJ1030) and the Earmarked Fund for China Agriculture Research System (CARS-09).

\section{REFERENCES}

[1] Makino, H., Furata, Y., Wakushima, H., Fujii, H., Saito, K., Kano, Y. 2003. Anti-allergic effect of Perilla frutescens and its active constituintes. Phytotherapy Research, 17 (2), 240 -243.

[2] Verspohl, E.J., Fujii, H., Homma, K., Buchwald-Werner, S. 2013. Testing of Perilla frutescens extract and Vicenin 2 for their antispasmodic effect. Phytomedicine, 20 (1), $427-431$.

[3] Jun, H.I., Kim, B.T., Song, G.S., Kim, Y.S. 2014. Structural characterization of phenolic antioxidants from purple perilla (Perilla frutescens var. acuta) leaves. Food Chemistry, 148 (2), 367-372.

[4] Park, M.H., Seol, N.G., Chang, P.S., Yoon, S.H., Lee, J. H. 2011. Effects of Roasting Conditions on the Physicochemical Properties and Volatile Distribution in Perilla Oils (Perilla frutescens var. japonica). Journal of Food Science, 76 (1), $808-816$.

[5] Longvah, T., Deosthale, Y.G. 1991. Chemical and nutritional studies on Hanshi (Perilla frutescens), a traditional oilseed from Northeast India. Journal of the American Oil Chemists' Society, 68 (2), 781-784.

[6] Tian, J., Zeng, X., Zhang, S., Wang, Y., Zhang, P., Lü, A., Peng, X. 2014. Regional variation in components and antioxidant and antifungal activities of Perilla frutescens essential oils in China. Industrial Crops and Products, 59 (2), 69-79.

[7] Ueda, H., Yamazaki, M. 2001. Anti-inflammatory and antiallergic actions by oral administration of a perilla leaf extract in mice. Bioscience, Biotechnology, and Biochemistry, 65 (2), 1673-1675.

[8] Banno, N., Akihisa, T., Tokuda, H., Yasukawa, K., Higashihara, H., Ukiya, M., Watanabe, K., Kimura, Y., Hasegawa, J., Nishino, H. 2004. Triterpene acids from the leaves of Perilla frutescens and their anti-inflammatory and antitumor-promoting effects. Bioscience, Biotechnology, and Biochemistry, 68 (2), 85-90.

[9] Meng, L., Lozano, Y.F., Gaydou, E.M., Li, B. 2009. 
Antioxidant activities of polyphenols extracted from Perilla frutescens varieties. Molecules, 14 (2), 133-140.

[10] Buchwald-Werner, S., Fujii, H., Schon, C., Doebis, C. 2012. Investigation of a Perilla frutescens special extract anti-inflammatory and immune-modulatory proper-ties. Agro FOOD Industry Hi Tech, 23 (2), 38-41.

[11] Hung, P.V., Hatcher, D.W., Barker, W. 2011. Phenolic acid composition of sprouted wheats by ultra-performance liquid chromatography (UPLC) and their antioxidant activities. Food Chemistry, 126 (2), 1896-1901.

[12] Liu, H.K., Cao, Y., Huang, W.N., Guo, Y.D., Kang, Y.F. 2013. Effect of ethylene on total phenolics, antioxidant activity, and the activity of metabolic enzymes in mung bean sprouts. European Food Research and Technology, 237 (2), 755-764.

[13] Osakabe, N., Yasuda, A., Natsume, M., Yoshikawa, T. 2004. Rosmarinic acid inhibits epidermal inflammatory responses: anticarcinogenic effect of Perilla frutescens extract in the murine twostage skin model. Carcinogenesis, 25 (1), 549-557.

[14] Kang, N.S., Lee, J.H. 2011. Characterization of phenolic phytochemicals and quality changes related to the harvest times from the leaves of Korean purple (Perilla frutescens). Food Chemistry, 124 (2), 556-562

[15] Gawlik-Dziki, U., Dziki, D., Nowak, R., Swieca, M., Olech, M., Pietrzak, W. 2016. Influence of sprouting and elicitation on phenolic acids profile and antioxidant activity of wheat seedlings. Journal of Cereal Science, 70 (2), 221-228.

[16] Liu, J.Y., Chen, Y.C., Lin, C.H., Kao, S.H. 2013. Perilla frutescens leaf extract inhibits mite major allergen Der $\mathrm{p} 2$-induced gene expression of pro-allergic and pro-inflammatory cytokines in human bronchial epithelial cell BEAS-2B. PLoS One 8, e77458.

[17] Zhang, G., Xu, Z., Gao, Y., Huang, X., Zou, Y., Yang, T. 2015. Effects of Germination on the Nutritional Properties, Phenolic Profiles, and Antioxidant Activities of Buckwheat. Journal of Food Science, 80 (2), 1111-1119.

[18] Cevallos-Casals, B.A., Cisneros-Zevallos, L. 2010. Impact of germination on phenolic content and antioxidant activity of 13 edible seed species. Food Chemistry, 119 (2), 1485-1490.

[19] Pająk, P., Socha, R., Gałkowska, D., Rożnowski, J., Fortuna, T. 2014. Phenolic profile and antioxidant activity in selected seeds and sprouts. Food Chemical, 143 (2), 300-306.

[20] Xu, B.J., Chang, S.K.C. 2007. A Comparative Study on Phenolic Profiles and Antioxidant Activities of Legumes as Affected by Extraction Solvents. Journal of Food Science, 72 (1), 159-166.

[21] Wei, J., Miao, H., Wang, Q. 2011. Effect of glucose on glucosinolates, antioxidants and metabolic enzymes in Brassica sprouts. Scientia Horticulturae, 129 (1), 535-540.

[22] Yang, M., Shen, Q., Li, L. Q., Huang, Y.Q., Cheung, H.Y. 2015. Phytochemical profiles, antioxidant activities of functional herb Abrus cantoniensis and Abrus mollis. Food Chemical, 177 (1), 304-312.

[23] Vale, A.P., idade, H., Pinto, M., Oliveira, M.B. 2014. Effect of sprouting and light cycle on antioxidant activity of Brassica oleracea varieties. Food Chemical, 165 (2), 379-387.

[24] Wang, X., Xie, K., Zhuang, H., Ye, R., Fang, Z., Feng, T. 2015. Volatile flavor compounds, total polyphenolic contents and antioxidant activities of a China gingko wine. Food Chemical, 182 (2), 41-46.

[25] Müller, L., Fröhlich, K., Böhm, V. 2011. Comparative antioxidant activities of carotenoids measured by ferric reducing antioxidant power (FRAP), ABTS bleaching assay ( $\alpha$ TEAC), DPPH assay and peroxyl radical scavenging assay. Food Chemical, 129 (2), $139-148$

[26] Zhang, Q.F., Zhang, Z.R., Cheung, H.Y. 2009. Antioxidant activity of Rhizoma Smilacis Glabrae extracts and its key constituentastilbin. Food Chemical, 115 (1), 297-303.

[27] Kaukovirta-Norja, A., Wilhelmsson, A., Poutanen, K. 2001. Germination: A means to improve the functionality of oat. Agricultural and Food Science, 13 (2), $100-112$

[28] Hong, E., Kim, G.H. 2010. Comparison of extraction conditions for phenolic, flavonoid content and determination of rosmarinic acid from Perilla frutescens var. acuta. International Journal of Food Science and Technology, 45 (2), 1353-1359.

[29] Aire, A., Fernandes, C., Carvalho, R., Bennett, R. N., Saavedra, M. J., Rosa, E.A.S. 2011. Seasonal Effects on Bioactive Compounds and Antioxidant Capacity of Six Economically Important Brassica Vegetables. Molecules, 16 (2), 6816-6832.

[30] Świeca, M. 2015. Production of ready-to-eat lentil sprouts with improved antioxidant capacity: Optimization of elicitation conditions with hydrogen peroxide. Food Chemical, 180 (2), 219-226.

[31] Aguilera, Y., Herrera, T., Liébana, R., Rebollo-Hernanz, M., Sanchez-Puelles, C., Martín-Cabrejas M. A. 2015. Impact of Melatonin Enrichment during Germination of Legumes on Bioactive Compounds and Antioxidant Activity. Journal of Agricultural and Food Chemistry, 63 (2), 7967-7974.

[32] Jang, H.W., Moon, J.K., Shibamoto, T. 2015. Analysis and Antioxidant Activity of Extracts from Broccoli (Brassica oleracea L.) Sprouts. Journal of Agricultural and Food Chemistry, 63 (1), 11691174.

[33] Martinez-Villaluenga, C., Peñas, E., Ciska, E., Piskula, M.K., Kozlowska, H., Vidal-Valverde, C., Frias, J. 2010. Time dependence of bioactive compounds and antioxidant capacity during germination of different cultivars of broccoli and radish seeds. Food Chemical, 120 (2), $710-716$

[34] Shi, L., Lei, Y., Srivastava, R., Qin, W., Chen, J.J. 2016. Gallic Acid Induces Apoptosis in Human Cervical Epithelial Cells Containing Human Papillomavirus Type 16 Episomes. Journal of Medical Virology, 88 (2), 127-134.

[35] Saqib, M., Iqbal, S., Mahmood, A., Akram, R. 2016. Theoretical Investigation for Exploring the Antioxidant Potential of Chlorogenic Acid: A Density Functional Theory Study. International Journal of Food Properties, 19 (1), 745-751.

[36] Gravinaa, H.D., Tafuria, N.F., Silva Júniora, A., Fiettoa, J.L.R., Oliveirac, T.T., Diazd, M.A.N., Almeida, M.R. 2011. In vitro assessment of the antiviral potential of trans-cinnamic acid, quercetin and morin against equid herpesvirus 1. Research in Veterinary Science, $91(1), 58-162$.

[37] Balupillai, A., Prasad, R.N., Ramasamy, K., Muthusamy, G., Shanmugham, M., Govindasamy, K., Gunaseelan, S. 2015. Caffeic Acid Inhibits UVB-induced Inflammation and Photocarcinogenesis Through Activation of Peroxisome Proliferator-activated Receptor- $\gamma$ in Mouse Skin. Photochemistry and Photobiology, 91, (2), 1458-1468.

[38] Liszt, K.I., Eder, R., Wendelin, S., Somoza, V. 2015. Identification of Catechin, Syringic Acid, and Procyanidin B2 in Wine as Stimulants of Gastric Acid Secretion. Journal of Agricultural and Food Chemistry, 63 (2), 7775-7783. 